\author{
Christine Marchese \\ SUNY - Nassau Community College \\ A3020, One Education Way, Garden City, NY \\ cmarc34@yahoo.com \\ Richard P. Smiraglia \\ School of Information Studies \\ University of Wisconsin Milwaukee \\ smiragli@uwm.edu
}

\title{
Boundary Objects: CWA, an HR Firm, and Emergent Vocabulary
}

\begin{abstract}
Knowledge organization structures are dependent upon domain-analytical processes for determining ontological imperatives. Boundary objects - terms used in multiple domains but understood differently in each — are ontological clash points. Cognitive Work Analysis is an effective qualitative methodology for domain analysis of a group of people who work together. CWA was used recently to understand the ontology of a human resources firm. Boundary objects from the taxonomy that emerged from narrative analysis are presented here for individual analysis.
\end{abstract}

\subsection{Introduction}

In a post-modern world, knowledge organization structures are dependent upon domain analytical processes, which are empirical methods for determining the ontological imperatives of groups of people laboring in common. Sometimes, domains clash. Especially, sometimes, when domains work in neighboring or simultaneous activities, their ontological imperatives clash. These clash points, terms that are used in both domains but understood differently in each, are called boundary objects. Such ontological clashes have been observed in healthcare settings, where divergent vocabularies must coexist. Examples were made apparent in Shepherd and Sampalli (2012); where different clinical groups were communicating together but using different ontological definitions of such simple terms as "fatigue."

\subsection{Cognitive Work Analysis}

Cognitive Work Analysis (Fidel and Pejtersen 2004) is an effective qualitative methodology for domain analysis of a group of people who work together. CWA was used recently, with measured success, to understand the ontology of a human resources firm (Marchese 2012). In three rounds of data collection, members of the firm were studied to understand their knowledge discovery process. First, structured interviews with both experts and non-experts were used to explore their information seeking and knowledge discovery practices. Participant observation followed, as well as a final open-ended focus group. Data were analyzed via the Cognitive Work Analysis (CWA) framework. Mapped into the CWA framework, observations supplied information about who knows what, and how, as well as what is done and why, and the means-ends analysis made it possible to analyze the system of knowledge creation and use.

CWA is particularly useful for revealing ways in which work-based ontologies mix or clash depending on the roles taken by participants (or "actors" for Mai (2008)) and the varying role-oriented work-dependent contextual barriers ("constraints" for Mai). For Mai (p. 19), actors are "humans that are involved in activities," which can involve explicit information seeking but more likely simply involve acquiring and using knowledge in particular ways. Analyzing actors and what they do reveals not only their information seeking or knowledge using contexts, but also the parameters bounding those activity-centered contexts. These are the "constraints," often situational, that both enable "actors to formulate questions and inquiries about particular phenomena" (p. 21) and, at the same time, limit inquiry through acculturation with the domain. In other words, people striving to work within a specific context are informed by their accumulated familiarity with the context. Questions that might arise from outsiders become constraining cultural influences for insiders. Simultaneously, the depth of acculturation of actors within a context fuels their explicit information needs as they strive to advance the activity while conserving the domain. In this way constraints both inhibit and enable actors. And, in this way, terminology becomes like pivot-points for ontological clashes - potential boundary objects that have divergent meaning to different actors, even in neighboring contexts. 


\subsection{Emergent taxonomy}

In Marchese's study the actors were experts and non-experts within the work environment, as well as clients acting externally. Thus colloquial conversation between an actor within the firm and a client might use relatively loose terminology lacking the constraints of the acculturation within the firm. The same actor might then turn to a colleague on the inside and use distinctly different (usually more precise) terminology to negotiate within the work context. Thus the taxonomy that emerged from the narration of the means-ends analysis was a mixed bag of terms. These terms are shown in Figure 1. Green highlighting identifies boundary object terms - verbs being used as nouns in conversation.

Table 1. Emergent vocabulary (Marchese 2012, 164)

\begin{tabular}{|l|l|l|}
\hline Articulate & Effective & Pipeline \\
\hline Break-out groups & Efficient & Process \\
\hline Broader audience & Employee levels & Report out \\
\hline Buckets & Executive development, Learning development, & Results \\
\hline Business skills & Focus groups & Roll-up of data \\
\hline Characters/role play & Gap scores & Rotate \\
\hline Check-ins & Individual behavior & Share methodology \\
\hline Cleaner & Interviews & Step-back \\
\hline Client's chart preference & Learning styles & Strong \\
\hline Data & Logs & Super days \\
\hline Descriptive & My lead - meetings -> product , task & Surveys \\
\hline Developmental priorities & Organizational Behavior & Team behavior \\
\hline Diversity & Phone bank & Thought process \\
\hline Divisions, levels, products, job families, business units & & \\
\hline
\end{tabular}

These terms, highlighted in green, are verbs - action words - that serve as pivots to external ontologies. All of these terms emerged from client calls in the HR firm - either from team client calls, or one expert client call. Thus, in each case the terms were used by the team to translate insider language for outsiders. For example (Marchese 2012, 107):

They wanted to be sure that they were able to articulate the business skill levels of their participants, and report out the information accurately.

... they wanted to be sure to appeal to everyone in the broader audience as well as articulate the particulars of each group

... The segment where they report out the results was focused on, and they debated how to share the methodology they used, or if they even should

and (p. 109):

Presenting back to the client, the format will be like a conversation ... the group will be led to articulate their feelings about the results being reported back. It would be broken down into stations, with the survey, interviews and focus groups being discussed individually. From there they will have breakout groups, and rotate them.

If this were a classification, some sort of $+/$ - symbol would be required to show that this is a point of departure and return to and from the other domain. That is, each of these terms can serve as a gateway in a KOS to the external from the inside, and to the internal from the outside.

\subsection{Discussion: Pivot-points and facets}

Much is made of the idea of facets in knowledge organization. The central idea is to add dimension to an otherwise flat hierarchical distribution of concepts. For example, in the Universal Decimal Classification (UDC) the symbol 625.714 means "towpaths." It falls within a hierarchy, of course, thus (MRF online): 
625.71 Kinds of ordinary road according to importance and purpose

625.714 Roads along watersides (embankments). Causeways. Towpaths

A towpath is a path built along the side of a canal where animals or vehicles can move on solid ground while towing a barge in a water-filled canal. In the UDC facets may be added using connecting symbols such as "+"or"/" or ":" to add dimension to a conceptual representation adding symbols from so-called auxiliaries or even by adding concepts together. So a towpath in New Hope Pennsylvania might add 734.811.4 Bucks County thus:

\subsection{4(734.811.4) Towpaths in Bucks County, Pennsylvania, US.}

This, however, does not tell us whether it is a towpath in 2013 with tourists sitting along it, or a towpath in 1864 with donkeys pulling armaments for the American Civil War. We could add a dimension of time thus:

$$
\text { 625.714(734.811.4)"1864" }
$$

and now we have expressed a place and a time, but still not whether we are dealing with building a towpath (the implication of 626.32 Hydraulic engineering) as opposed to 625.714 for kinds of roads, or whether we mean instead navigating a towpath. We could add 536.78 "Journey in straight line" to show we mean navigating. Now we have:

$$
\text { 536.78+625.714(734.811.4)"1864” }
$$

The increasing complexity of this example is intended to convey both the enabling and the constraints of conventional facets. Indeed, UDC is flexible enough to allow us to continue to manipulate the symbol until it incorporates all necessary dimensions.

So we see that in faceted classification, each point of synthesis is a turning point thus:

Navigate <--> Towpath <--> Bucks County Pennsylvania <--> American Civil War

Indeed, "towpath" itself is a turning point because we know at least two different expressions of the concept with different meanings:

626.32 (hydraulic engineering, shape of canals, towpath) < -- > 625.714 (purpose of road, along water, towpath)

Similarly, the CWA in the present study has illuminated the pivot points, or perhaps we should say the turning points, where border objects allow inter-domain penetration in either direction, better known as direct communication. But translation is required in work-based systems, to allow actors from different domains to communicate across domain boundaries.

We can turn now to examples from the present research using the highlighted passages above. "Articulate" for example can mean:

$$
\begin{aligned}
& \text { "Share" } \\
& \text { "Report out" } \\
& \text { "Break out" and } \\
& \text { "Rotate" }
\end{aligned}
$$

and, a pivot-point for actors,

$$
\text { "Role-play." }
$$

In this example we see that to "articulate" is to enumerate with clarity, but from internal experts to internal nonexperts it means "share," while from internal experts to external clients it means "report out." Internally, to "articulate" requires the actors to "break out," which means to separate into different discussion encounters, as well as to "rotate," which means literally to turn from internal to external context. "Role-play" of course means maximizing the activities of actors in the domains, so as to facilitate articulation. Figure 1 is a visualization of the 
process by which "articulate" acts as a pivot point.

Figure 1. "Articulate" as a pivot point

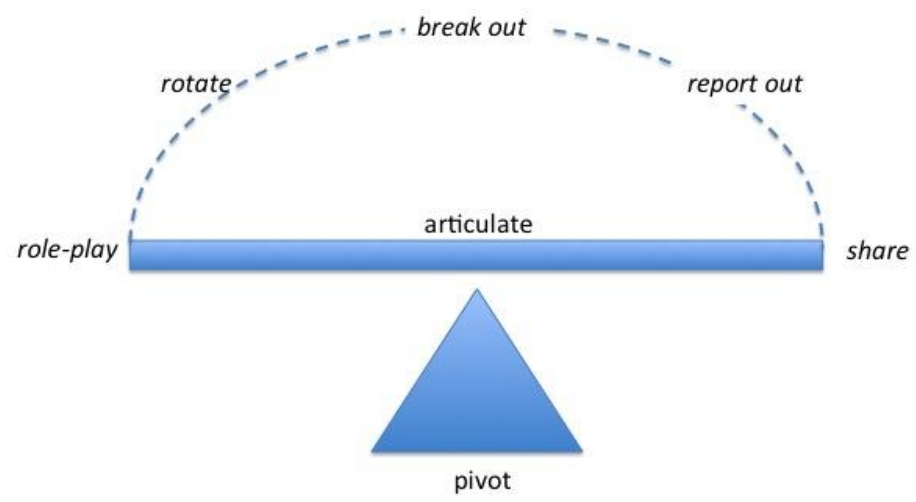

Were our emergent taxonomy to become a classification, "articulate" would become a pivot-point for a facet that incorporated these dimension-shifting activities, much in the way that synthesizing a UDC number allows complexity to pile up.

In the next example, the usage of the term diversity is more closely examined:

She was currently pulling information for a new diversity program (which started a lively conversation for all to 'define diversity') among other client-related tasks (p. 64).

There is a brief loop-back to the simulations as they pertain to diversity. Discussion ensues regarding client terms and context, such as women, multicultural, POC (people of color), etc. and their meanings. They look beyond their own circle and interpretation to gauge what the client may be thinking and looking for (p. 78).

The discussion then takes another turn to include diversity from the perspective of hiring people with different training and backgrounds. This will be a shift from their current and previous staffing. They want to fill specific needs, and there has to be different focus, and higher efficiency (pp. 80-81).

Diversity definitions could possibly be applied here - client terms and context should be taken into account such as women, multicultural, POC (people of color), and so on. She asks Melissa to continue to look into definitions of diversity to see what she can find (p. 111).

Melissa offers an example of how the process works in the course of her day. She is currently researching items related to corporate diversity for a diversity program they may be creating at ER\&A for a client. Melissa begins by going on the network to see if there are any files that may contain the word 'diversity' for any kind of background. She explains that this can be a time consuming process because there are so many places to look (p. 122).

Dan calls in, and is on speakerphone to help, and everyone ends up migrating over to Melissa's desk and the surrounding area to discuss diversity, definitions, files, and work (p. 123). 
In this example, the term "diversity" acts not only as a pivot point to the external from the internal, but also as a touch point of sorts within the internal environment, its actors and roles. Figure 2 is a visualization of "diversity" as a pivot point.

Figure 2. "Diversity" as a pivot point

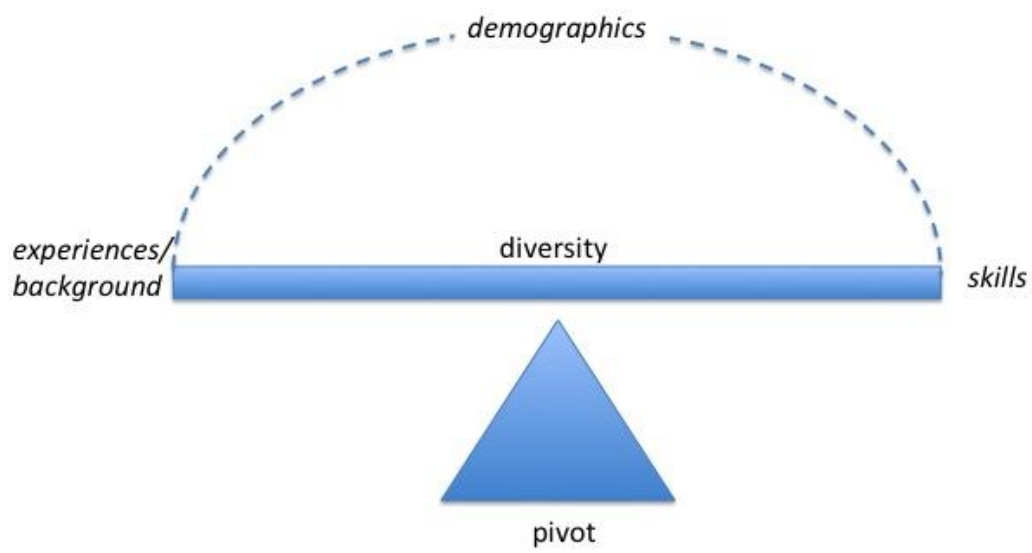

Not quite homonymy, the term almost morphs as it comes under different usage, with different implied and expressed meanings found in the narrative. The term is examined in the context of what it might mean to the client, what it means to the organization, what is has meant internally as well as perhaps what it should mean, both internally and externally. This hints at the use of alternate definitions even within their own environment depending upon the application of the term. Diversity can encompass many things in many contexts, and internal discussions among the actors within their environment attempt to touch upon many of them. The CWA methodology lent itself well to the discovery of the changing use of the term 'diversity' through the guiding analysis provided by the onion model.

Behavior emerged from the CWA as another interesting pivotal term to examine. Information science and knowledge organization discuss behavior in several contexts-information seeking behavior, knowledge creating behavior, and so forth. In these contexts it is always referred to as a verb. Individual behavior, team behavior, and organizational behavior are all terminology cited as repeatedly used in the work environment from Marchese's study (2012, 76, 107). Examples include:

The candidate has become belligerent during the simulation and has been bullying the role players (acting as employees). While the role-players appear to be handling the behavior [of the candidate] well, the group discusses the situation and tries to decide upon what feedback to give (p. 84).

Another theme that becomes prominent from the interviews is the three distinct functional areas in the organization - technology, administrative support, and subject matter expertise which in this case is organizational behavior (p. 103)

In this instance organizational behavior is referred to as a discipline. 


\begin{abstract}
As they discussed the findings, they focused on several key areas. Individual behavior was weighed in relation to team behavior, and organizational behavior was looked at as a whole. It was not enough to look at the resulting behaviors. They closely examined the
\end{abstract} thought process behind each interaction, as well as the thought process behind why they asked what they did (p. 106).

There was discussion regarding several known instruments for predicting employee behavior... They were looking at individual, team, and organizational behavior for this project (p. 108).

It became obvious that the experts did indeed see the more detailed topics when engaging in information seeking behaviors (p. 145).

In this last example behavior is referred to in the context of information seeking, a foundation of the methodology used for this study.

The terms centered on behavior are also highlighted in Table 1's listing of the emergent vocabulary. The terms came from team-based work interactions as well as individual, further emphasizing the ability of the organization to utilize the vocabulary for both internal and external communication and work processes.

\footnotetext{
It is clear that the team has a common vocabulary, and that this is largely made up of identifiers, such as "behavior" (and various modified usages of that term), tools, such as "interviews" and "break-out groups," and action terms such as "articulate, and "report out." These are examples of the familiar terms from their backgrounds and training - their work discipline. This is a language all its own, that becomes second nature to people working in the field of strategic management, more specifically consulting in strategic management. This also begins to further support their strategies for managing their knowledge (p. 162).
}

Several references were also made to behavioral interviewing processes, when participants were asked to describe their skill sets and backgrounds (pp. 93- 94). A visualization of "behavior" as a pivot point appears in Figure 3.

Figure 3. "Behavior" as a pivot point

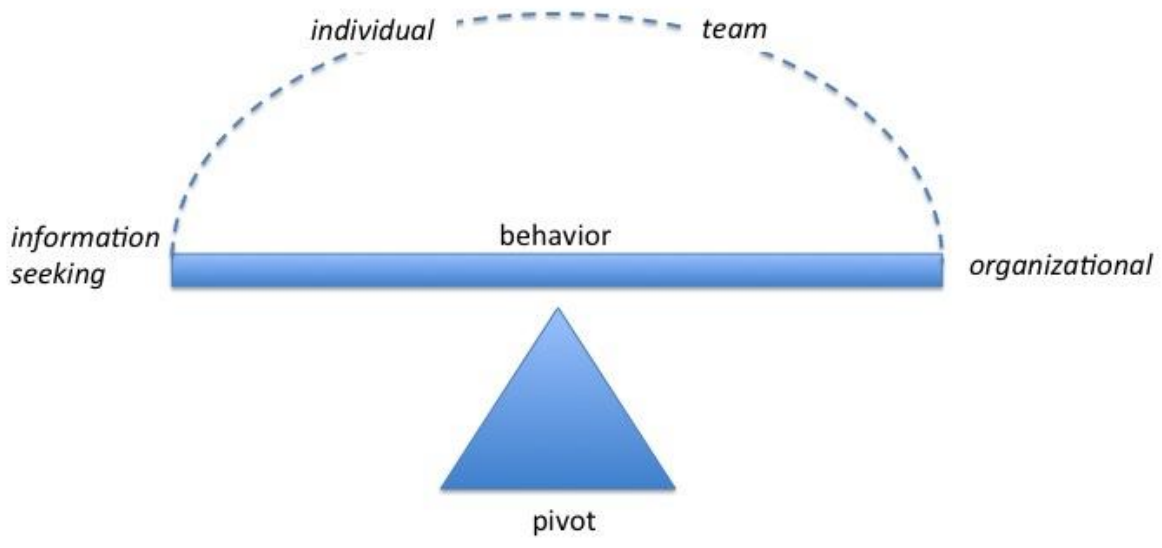

In the latter two cases- - diversity" and "behavior" we see echoes of homonymy-the linguistic phenomenon in which a singe word can have different meanings. More to the point, with these two examples we see the case of a single phenomenon that appears in different locations within a classification. The pivot points from the term toward all of the loci in which the phenomenon might appear in a classification. 


\subsection{Conclusions: The Value of Boundary Objects}

We have yet quite a lot to learn from actual actors about the ways in which they classify their own information needs and knowledge bases. CWA is a useful methodology for doing so. So far there have been few studies utilizing the method. More clearly are required. The evidence from the present study, although limited by the domain constraints, is sufficient to demonstrate the efficacy of the method. The natural language of the subjects working together in a single work domain emerges from means-ends analysis to demonstrate the roles of boundary objects.

What then can the KO community learn from studying boundary objects? First, we can learn where the pivot points are-we have been calling these facets in general classifications, but in fact they are the doors of perception that can lead from one domain to another, to another, etc. They need not continue to be ontological clash points. Rather, they can be understood as opportunities for inter-domain communication. The pivots allow us to increase perception by adding context. They allow a single morphing concept to stand for many things at once to different actors. Pivots also allow us to enhance depth - or enumerate intension - in, between, and among domains. We can use facets to express complex concepts, that has long been demonstrated. But more importantly, CWA teaches us that we can use facets to provide bridges between associated domains upon which users can navigate boundary objects.

\section{REFERENCES}

Fidel, Raya and Annelise Mark Pejtersen. 2004. From information behaviour research to the design of information systems: the cognitive work analysis framework. Information Research Volume 10, No. 1 Paper210.

Mai, Jens-Erik. 2008. Actors,domains, and constraints in the design and construction of controlled vocabularies. Knowledge organization 35: 16-29.

Marchese, Christine. 2012. Impact of Organizational Environment on Knowledge Representation and Use: Cognitive Work Analysis of a Management Consulting Firm. Ph.D. dissertation, Long Island University.

Shepherd, Michael and Tara Sampalli. 2012. Ontology as boundary object. In . In A. Neelameghan and K.S. Raghavan eds. Categories, contexts, and relations in knowledge organization: Proceedings of the Twelfth International ISKO Conference, 6-9 August 2012, Mysore, India. Advances in knowledge organization 13. Würzburg: Ergon Verlag, 2012, pp.131-37.

Universal Decimal Classification. 2013. MRF editor. 